\title{
Issues in competence and pre-service teacher education. Part 2. The assessment of teaching practice
}

\author{
W. J. Fraser \\ University of Pretoria, South Africa \\ e-mail:wfraser@hakuna.up.ac.za \\ R. Killen \\ University of Newcastle, Australia \\ e-mail: roy.killen@newcastle.edu.au
}

\author{
M. M. Nieman \\ University of South AfricaSouth Africa \\ e-mail:niemamm@unisa.ac.za
}

\begin{abstract}
One of the challenges facing teacher educators is to develop assessment practices that will minimise the uncertainty and subjectivity associated with assessing teacher competence, and that will allow them to distinguish clearly between those who are competent and those who are not (yet) competent. According to the Norms and standards for educators (Department of Education 2000), teaching practice should form an integral part of teacher education programmes and should be regarded as a way in which to assess all the different roles of educators as part of the integrated and applied assessment task. This is a major challenge since the assessor must consider several modalities such as the selection of suitable measuring instruments, the question of which competences should be assessed, the advantages and disadvantages of the direct observation of teaching performance and the relevant levels of performance. This article explores only some of the many issues related to teaching practice and the assessment thereof.
\end{abstract}

\section{INTRODUCTION}

An outcomes-based approach to education in South Africa was introduced in an effort to improve on the education that, for so many inhabitants of the country, had been overly academic and had failed to prepare them adequately to enter into the job market. As was explained in the preceding article ('Can outcomes-based programmes produce competent teachers?', the Norms and standards for educators (Department of Education 2000) was adopted in 2000 as a national policy in an attempt to improve teacher education in South Africa by, inter alia, focusing more on the actual workplace. Not only does this document clearly state that all teacher education programmes need to concentrate on the competences required in the workplace, but it also stipulates that teaching practice, that is, 'periods of time spent in the workplace (schools or other sites of learning)' should be regarded as a mode of delivery through which all the different roles of educators should be assessed as a part of the integrated and applied assessment task 
(Department of Education 1998, 115; 127). Integrated and applied assessment is regarded as a form of formative and summative assessment which permits learners to demonstrate their applied competence (Department of Education 1998, 112).

Although the Norms and standards for educators (Department of Education 1998, 110-112) demands that the applied and integrated competence (i.e. the ability to integrate theory and practice in teaching) of student teachers should be assessed, it provides only vague guidelines on how this should be done. The question of how a valid judgment can be made about a student's readiness to enter into the teaching profession still needs to be answered. It seems that the answer to this question is not a straightforward one, especially if one considers that assessing professional work is much more difficult than assessing work based on a skills components model (Bailey 1997, 41). Bailey (1997, 41) cites the following to explain why this is the case: 'For example, the skills of a pilot can be thought of as a list of competencies - taking off, climbing, turning, descending, and landing. It is easy to devise a test to determine whether a student has mastered these tasks. But the pilot must also decide when to land or when it might make more sense not to take off. These matters of judgment are more difficult and costly to assess.' This same dilemma exists in assessment practices related to teacher training.

\section{STATEMENT OF THE PROBLEM}

The roots of competence-based assessment lie in the passing of competence legislation for teacher certification in many states in the US in the 1970s and early 1980s (Wiersma and Gibney 1985, 59). While competence-based training and assessment were initially seen as a panacea for reforming and uplifting teacher education and eventually education in general, it was later met with scepticism because of its behaviouristic underpinning and the way in which the complex professional tasks in which teachers engaged, were broken down into competencies that could be performed in a mechanical manner (Eltis 1997, 126; 128). Eltis $(1997,121)$, however, notes 'the emergence of competencies as a "new" force in education and training' in recent years. He points out that the new competency agenda differs considerably from the previous technicist approaches to competency-based education of the 1960s. The traditional approach has been developed to become a 'new' more holistic - or integrated - approach that involves assessing a combination of attributes (knowledge, capabilities, skills and attitudes) and the performance of tasks (that can be broadly defined and include professional judgement) at an appropriate level or standard, in a particular type of situation, usually practice (Eltis 1997, 130).

To differentiate between the former and the latter approach to competencebased education, the term 'competence' is used rather that the more performance specific term 'competency' (Evans 1994, 6). The Norms and standards for 
educators (Department of Education1998, 26) supports this notion and propagates integrated and applied assessments as opposed to mechanical assessments of simple behaviours (cf. p. 112).

For the extended concept of competence, to guide the development and implementation of a training programme, the competences central to the programme need to be defined with precision so that they can be assessed. This implies that descriptions of competences should be easy to understand, straightforward and flexible, permit direct observation, be expressed as outcomes, be transferable from setting to setting, and meet national, as opposed to local, standards (Norris 1991, 331). It is only when all these conditions are met that training programmes can have Spady's $(1994,10)$ clarity of focus which is necessary for preparing learners for their occupational roles. This preparation of learners, implies the learners must be assessed in order to determine exactly how prepared they are for the workplace. In this regard the Technical Committee on the revision of norms and standards for educators (Department of Education 1998, 26) states: 'When we assess a learner's competence, we make observations of, and inferences from the learner's performance'. This statement contains the essence of the problem to be explored in this article, namely how to determine whether a student is competent enough to perform the duties and functions of the profession at the levels of mastery or competence required by the profession? In order to answer this question, this article will explore competence-based assessment and refer to teaching practice as one of the options available to teacher educators to measure the beginning level competence of teachers in the South African context.

\section{ASSESSING COMPETENCE IN PRACTICE}

The importance of establishing criteria for performance and standards for competence

As already stated, the challenges facing teacher educators is the development of assessment criteria that reduce the uncertainty involved in assessing teacher competence and clearly distinguishing between those who are competent and those who are not (yet) competent. This is echoed by Ilott and Murphy $(1999,89)$ who argue as follows: 'Our central argument is that however good the programme, there must be an open, fair assessment system to ensure that those who fail to cross the threshold of minimum competence receive a fail grade. This requirement warrants dependable, robust assessment procedures throughout the course'.

In competence-based assessment, the purpose of assessment is the collection of sufficient evidence of workplace performance to demonstrate that individuals can perform or behave to the specified standards in a specific role (Fletcher 1997, 26). An essential part of competence-based assessment is therefore comparing the learner's knowledge and performance with specific descriptions of acceptable evidence or expectations, stated explicitly in performance criteria and standards of competence (Mitchell 1990, 34; Fletcher 1997, 41-45; Marquand 1998, 149). 
According to Fletcher $(1997,41)$ these criteria are 'outcomes-based, reflecting expectations of workplace performance, and have been agreed through consultation with role holders'. They also reflect an agreed benchmark of competence. This implies that the criteria and standards which specify how, how well or under which conditions a particular task should be executed or how a particular role should be fulfilled can be described unambiguously. In the case of assessing the competence of teachers, it is necessary to consider both their performance in action (e.g., the teacher's ability to explain conceptual knowledge) and the quality of the products they produce to support their teaching (e.g. a learning programme developed by the teacher). In both cases, the assessor must specify performance criteria and standards and use the evidence gathered from assessing activities or performance to determine whether the candidate meets the required criteria (Fraser 1995, 12). It is important that these criteria are 'attainable, observable and measurable', and that they arise directly from a consideration of authentic performance competences (Fraser 1995, 12). These assessment processes can be quite complex because, as Marquand $(1998,149)$ puts it: 'It is alleged that the whole is lost in dividing the work role into a series of components in this way and providing assessment criteria for each', while Norris $(1991,336)$ points out that, 'there is a massive mismatch between the appealing language of precision that surrounds competency or performance-based programmes and the imprecise, approximate and often arbitrary character of testing when applied to human capabilities'.

\section{The selection of suitable measuring instruments}

Assessment has to be closely linked to actual or potential on-the-job performance (Foyster 1990, 48; Fletcher 1997, 50) and an assessment instrument has to be capable of generating appropriate evidence. According to Fraser $(1995,12)$ and Siebörger and Macintosh $(1998,5)$ assessment is essentially about developing measuring instruments, generating evidence and making judgements. It can thus be argued that one of the most fundamental and crucial aspects of the assessment and evaluation of competence is the selection of suitable measuring instruments to generate evidence in support of decisions about competent or incompetent behaviour (Fraser 1995, 12; Fraser 1996, 82). The reliability of the assessment process and the validity of the subsequent decisions will largely be determined by the congruence between the task and function being assessed and the measuring devices selected to assess the performance.

It seems unlikely that one assessment tool or instrument will ever be adequate enough to measure all the skills and competences of a student teacher. Therefore, to assess the competence of a student teacher it is necessary to have suitable measuring instruments, to apply them in circumstances that will generate reliable evidence and to interpret that evidence in valid and defensible ways. If this is not done, a difference between the evidence which can be reasonably and reliably collected from performance and the evidence needed to make inferences about 
competence can produce the so-called 'assessment gap' (Understanding Knowledge 1990, 2). When assessing competence, assessors should ensure that their evidence gathering strategies are suited to the performances being assessed and the conditions under which they are being performed (Fraser 1995, 12; Fraser 1996, 82). According to Fletcher $(1997,60)$ the best evidence on a person's competence comes from the actual workplace performance. Hence there are frequent calls for the assessment of the competence of teacher education students to be based on their performance in authentic teaching situations (Eltis 1997, 130).

Arguments such as these lead to the logical suggestion that, as a minimum requirement for certification, teacher education students should be able to demonstrate competence in appropriate 'practice teaching' situations. Virtually all pre-service teacher education programmes recognise this need to expose students to the reality of the classrooms in which they will eventually teach and most programmes assess students during their teaching practice.

This component of teacher education is entirely consistent with the general principles of competency-based professional education outlined in the preceding article 'Can outcomes-based education produce competent teachers?'. However, there is a peculiar situation in South Africa. The Norms and standards for educators (Department of Education 1998, 11) recognises teaching practice as an 'essential feature that should be included in all educator programmes' and indicates that is should be seen as 'a mode of delivery through which all the different roles of educators should be developed and assessed' (cf. p.12). There is a further requirement that 'Ultimately, the qualification should reflect an applied and integrated competence. This demonstrated ability to integrate theory with practice in teaching must be assessed within all educator qualifications' (Department of Education 2000, 13). However, the statement that 'no competences are specifically associated with it [teaching practice]' is apparently contradictory (Department of Education 2000,11). The confusion arising from this statement is generated by the different interpretations that can be placed on the phrase 'associated with'. It seems that the Norms and standards are suggesting that no competences should be solely associated with practice teaching, but that practice teaching should incorporate (at least indirectly or implicitly) all the competences that are expected of teacher education students. This view is reinforced by the statement that 'applied competence refers to the ability to integrate the discrete competences which constitute each of the seven educator roles' (Department of Education 2000, 10) and the requirement that 'competence in a role is assessed, rather than simply the ability to perform a discrete competence'.

There is a further requirement that the seven educator roles should be assessed in 'an integrated and applied manner' (p. 10). To resolve the apparent contradiction lying in the fact that teacher education students are expected to demonstrate all 132 competences listed in the Norms and standards for educators but that these 
competences are not to be used as a 'checklist' for determining overall competence we need to look more closely at the teaching practice component of teacher education programmes.

\section{TEACHING PRACTICE}

In many teacher education programmes in South Africa and elsewhere, teaching practice is a fixed-time, credit-bearing 'course' or 'subject' that students undertake with little supervision or guidance. Because of the time and cost involved in sending teacher educators into schools to supervise students and because of the reluctance of many teacher educators to venture into schools in localities that are viewed as unsafe, the level of supervision of most teacher education students in South Africa is minimal. This makes it virtually impossible to achieve the aims of the Norms and standards to make teaching practice an opportunity for student teachers to 'experience and demonstrate the integration of the knowledge, skills and values developed in the entire curriculum' (Department of Education 1998, 127). Rather than being a well-structured learning experience and an opportunity for authentic assessment, teaching practice for many students becomes a demoralising and sometimes very frightening experience (Killen and Steyn 2001; Marais and Meier 2004). Whether or not teaching practice contributes to the development of a particular student's competence is usually uncertain and unknown.

There are a number of ways in which this problem can be dealt with but any attempt to improve the situation should be firmly grounded in the framework established by the Norms and standards for educators. As a starting point, we should consider the timing and length of teaching practice. The Norms and standards for educators is consistent with the principles of OBE in not stipulating any minimum time to be spent in the workplace, but specifying that time devoted to site-based teaching experience should vary according to the needs of individual student teachers (Department of Education 1998, 127). This might seem a rather outlandish proposal, but it makes sense for several reasons. It is a fact that some students learn much more quickly from their site-based experiences than do others. It is also a fact that some students can demonstrate applied competence with much less practice than others. The opposite is also true. With a little work and imagination, institutions will probably find that a flexible approach to site-based experience (both in terms of total time and the 'chunking' of that time) is both possible and beneficial. For example, some students would probably benefit more from a practicum that is broken up over an extended period of time than from a block practicum. A flexible approach to teaching practice makes it possible to work more co-operatively with schools and to more readily accommodate the academic staff who have to juggle supervising student teachers and a heavy workload. With this kind of flexibility, teaching practice begins to be seen as more important and productive by teachers, lecturers and teacher education students. 
This may lead to innovations such as the so-called teaching internships in which final-year teacher education students are expected to take on the full responsibilities of a teacher (Killen and Richards 1996).

A strong feature of the Norms and standards approach to assessment, and one that aligns well with Spady's (Spady and Schlebusch 1999, 41) approach to assessment, is the insistence that assessment should focus on demonstrations of applied competence within the particular student's fields of specialisation. This is a major challenge. At a basic level, this means that the assessment of discrete competencies, or the assessment of role performance in a generic context should be undertaken for formative purposes only. Ultimately, student teachers must demonstrate complex learning that integrates practical, foundational and reflexive competencies at the same time as it integrates different educator roles. This will require a diverse range of evidence that is collected over time, in authentic contexts related to the specialist role of the educator, and from which it can be inferred that the trainee educator has the ability to adapt practice to changing circumstances. As Fletcher $(1997,41)$ puts it: 'Is it the process of performance or the outcome of performance you want to assess? Do you want a one-off demonstration of that performance, or do you want to know that people can perform to a specified standard over a period of time? . . . Will you need to assess simply what people do or also how well it is done?' All of this is a tall order.

In addition to the question of what competences should be assessed during the teaching practicum, there is also the question of what priorities should be assigned to the various competences that are deemed to be important. Even when there is general agreement on competences and assessment criteria, different assessors often have different priorities (McIntyre and Norris 1980; Barrett 1986). For example, one teacher education programme may consider classroom management the most important area to be evaluated while another may place a higher priority on subject matter knowledge.

Fletcher $(1997,41)$ reminds us that a further key point to consider is whether we are assessing competence or excellence. This means that assessors should decide whether common standards of performance which can be used as a benchmark for competent performers should be set, or whether a further benchmark of excellence should be added. The Norms and standards for educators (Department of Education 2000) does not give any guidelines on this.

\section{Advantages and disadvantages of the direct observation of teaching performance}

We have to accept that 'different methods of assessment provide different types of evidence about candidates' capabilities' (Assessment of Competence 1989, 5). The direct observation of work activities and the taking of competency tests should be regarded as two important and complementary evidence-gathering methods in the assessment of competence (Fennell 1990, 42). Numerous assessment techniques 
are suitable for continuous assessment at the site of learning and all education and training practitioners should have a sound knowledge of what each technique offers. However, the key issue to be decided is whether or not any form of indirect measurement of competency can produce sufficiently reliable evidence from which valid inferences can be drawn about ultimate on-the-job competency.

To obtain evidence of the competence of teachers we have essentially three choices: direct observation of various aspects of their teaching (including observation of the products they produce, such as lesson plans or learning resources); assessment of their background knowledge; or assessment of the learning of their students. Each of these choices has its advantages and limitations, many of which are linked to the attitudes of the teachers themselves. Few teachers are prepared to have their competence judged on the basis of the learning of their students even though 'it seems illogical to suggest that someone could claim to be teaching if his or her students are not learning' (Killen 2002, 14). Similarly, few teachers relish the idea that their knowledge of the subject matter they teach or their knowledge of learning theories or pedagogy or any other aspect of teaching should be assessed after they have been employed. This leaves direct observation as the only means of gathering evidence of teachers' competence and, at least in South Africa, this is a very contentious issue for those who are already employed as teachers (Matshidiso and Teu 2002; Teu and Legotlo 2002). However, controversy over the methods that should be employed to evaluate experienced teachers should not necessarily prevent their use in the case of student teachers.

Despite the reluctance of many teachers to have their classroom practices placed under scrutiny, the direct observation of a worker at a given task is regarded by many professions as one of the most effective and relevant means of assessing competence (Stedman 1985, 201; Fletcher 1997, 60). In the case of teaching, there is considerable evidence that classroom observation scales can be reliable instruments for measuring classroom behaviours and for obtaining descriptive measures of these processes (Brophy et al. 1975, 880-881; Luke et al. 1998). Various techniques have been developed for recording behaviours deemed to be present or absent during the observation period, for generating summary ratings based on these observations, and for noting the extent to which the teacher displays certain personal attributes that are considered important in teaching (Stodolsky 1984, 11; Killen 1991). Note here the emphasis on 'behaviours absent or present during the observation period'. One of the weaknesses of observation of performance is that opportunities for student teachers to demonstrate competence across the full range of activities may be limited (Fletcher 1997, 63). However, the fact that a specific and required behaviour has not been observed does not necessarily imply that a candidate is not in possession of the required knowledge and skills to demonstrate the competence. It is rather a matter of 'competence' and 'performance' as Norris (1991, 333) and Messick (1984, 227) understands it. Competence is about potential, while performance reflects the actual behaviour of a candidate on a particular occasion. Conklin $(1985,13)$ suggests that 
'demonstration of competency in actual teaching situations while under observation' has the advantage that both the outcomes and products of an activity, as well as the processes involved in the delivery of the final products, may be appraised. This approach to teacher assessment rests on the assumption that the characteristics of 'good' or 'effective' teaching are known and recognisable (Stodolsky 1984, 11) and there is considerable evidence to support that claim (Wittrock 1986; Good and Brophy 1991; Barry and King 1998; Department of Education and Training 2003).

According to Kagan, in Ryan and Kuhs (1993, 78), classroom observations play an important role in the screening of pre-service teachers but have limited potential in predicting future effectiveness because they focus only on the lowest level of professional development of the teacher. Whitty and Willmott $(1991,314)$ remind us that such an approach has become inappropriate in the assessment of high-level professional skills, and that the knowledge and understanding essential to performance and skills cannot always be assessed through direct observation in the workplace only. One has to take into consideration that it is also much easier to assess teachers' knowledge about content, pedagogy, and specific learners than to assess their performance in delivering instruction that will generate the desired learning outcomes and personal responses (Hollins 1993, 97).

Stodolsky (1984) questions the stability, and therefore the reliability of observation as measurement technique in the assessment of student teachers. She emphasises the importance of multiple observations to ensure reliable estimates of teacher behaviours, but immediately reminds us that the sheer number of observations will not improve reliability (internal consistency) estimates unless the observations are taken under instructional conditions (on-the-job performance) requiring a similar repertoire of teaching behaviour (Stodolsky 1984, 13). It would therefore be inappropriate to assume that a representative picture of a teacher's competence can be obtained from a small number of observations, especially when these observations are carried out across different subjects as would typically be the case with Foundation Phase or Intermediate Phase teachers in South Africa.

\section{Levels of performance (cut-scores or cut-points)}

Van der Wagen and Ridley (1997, 24-25) suggest that functional analyses or job or task analyses can be used to determine acceptable standards of excellence against which to judge competence, with the intention of minimising risk and enhancing efficiency in authentic situations. Quite clearly, this requires a definition of what constitutes 'acceptable standards of excellence'. It is also likely to lead to a recognition that these standards will not necessarily be static but might change as community or professional expectations change. This raises the issue of the role of 'norms' (defined either qualitatively or quantitatively) in the definition of levels of 
competence. It also raises the very practical issue of deciding whether to base assessment decisions on 'cut-points' (multiple levels of performance) or 'cutscores' (single minimum levels of performance).

Glass $(1978,251)$ attacks the advocates of the 'minimal competence' paradigm, claiming that those who base criterion scores on a concept of minimal competence are wrong for two reasons, namely that the model has no foundation in psychology, and that assessors disagree on the arbitrariness of the values when minimal competence has to be specified. She concludes that the idea of minimal competence is bad logic and even worse psychologically, and that the language of performance standards is pseudo quantification, a meaningless application of numbers to a question not prepared for quantitative analysis (Glass 1978, 238). Even in the opening paragraphs of the well-documented article Standards and Criteria, Glass (1978, 237-238) writes that mastery or competence cannot be determined in statistical or psychological ways, and that 'criterion levels' or standards cannot be determined other than arbitrarily. This supports Spady's (1994, 32) move away from the setting of cut-scores as levels of minimum competence but does little to resolve the problem of distinguishing between excellence (exceeding minimum competence requirements) and inadequacy (incompetence) in teaching and teacher education.

There is, however, another factor to be taken into consideration - that of the relationship between competency testing and on-the-job success (University of Pretoria and National Education Group 2000, 5-8). Conklin (1985, 14) claims that the reliability of estimates of teacher success are almost impossible to determine, and that passing a competency test does not guarantee that the candidate will be a successful teacher, only that he or she will be less likely to be incompetent. What is the value of high performance scores in certain fields of specialisation? Are high scores for teaching practice, the underpinning theory supporting pedagogy, learning mediation or classroom management guarantees of teaching success? There are indications that high scores in mathematics, reading and writing will not necessarily guarantee good teaching, but that low performance scores will almost certainly lead to poor teaching (Conklin 1985, 15). If low performance scores can be regarded as sure predictors of poor performance, then the establishment of a cutscore as a measure of elimination is surely justifiable. However, the problem of defining appropriate cut-scores still remains.

There is a tacit assumption that the assessment of foundational knowledge (through written assignments and examinations) and perhaps the assessment of skills in artificial situations (such as peer teaching) are enough to enable an institution to certify that the graduates of its programme are competent to teach. Rarely is the assessment of teaching performance during the practicum thorough enough or comprehensive enough to meet the traditional assessment criteria of reliability, validity and fairness. If the assumptions behind this approach to teacher education are to be defensible, we must examine very closely the relationship between the things that are assessed and the competences that ultimately have to be 
demonstrated in real teaching. We must define teaching competences precisely and we have to design back from these competences to ensure that our teaching and the learning experiences of our students will enable them to achieve the required competences. We must also align outcomes, teaching and assessment in a manner similar to that suggested by Killen (2002). In this process, we will have to make critical decisions about cut-off scores - when will 'good' be 'good enough'?

\section{SUMMARY}

In this article we have explored and discussed a number of issues pertaining to competence, pre-service teacher education and the assessment of teaching practice. There seems to be growing support worldwide for standards-referenced and performance-based systems of teacher assessment (both pre-service and in-service) (Eltis 1997, 146). The standards on which these systems are based define what teachers or prospective teachers need to know and be able to do. They cover knowledge, understanding, skills, attitudes, values and dispositions that are essential for competent teaching in particular contexts. There is also a general agreement that competence cannot be assessed reliably unless it is based on clearly defined performance indicators that allow for variations in teaching contexts. These indicators should describe a range of possible ways in which a teacher might demonstrate that he or she has achieved the standards that define competence.

The Norms and standards for educators attempts to describe teaching competence and provide a framework for the development of outcomes-based programmes that will contribute to the development of competent teachers. In this and the foregoing article, it has been argued that teacher education graduates are unlikely to be able to demonstrate applied competence across the range of teacher roles defined in the Norms and standards unless their teacher education programmes and training are explicitly competence-based and unless assessment of competence is standards-referenced. This argument was based on the fact that it is possible to define and develop teacher competence. Similarly, it is possible to develop teacher competence; it is reasonable to expect teacher education students to demonstrate appropriate levels of competence before they graduate and that this competence should be defined in terms of what teachers do with their learners in their classrooms (their performance). This performance can then be described by performance indicators that are more than a simple checklist and performance judged against explicit public standards and assessment criteria.

It is unlikely that the requirement of the Norms and standards requirements that beginning teachers should be competent in each of the seven educator roles can be met without systematic and sustained observations in classrooms. This is costly and time-consuming, but necessary if we are to pay anything more than lip-service to the idea that graduates of teacher education programmes should be competent enough to provide the quality of education referred to in the 1995 White Paper. If it is not possible to allow for school-based assessment to guarantee that graduates are 
sufficiently competent in each of the roles defined in the Norms and standards for educators then the next best thing would be to link every module in the programme to a practical school-based assignment.

\section{REFERENCES}

Assessment of Competence.1989. Development of assessable standards for national certification. Guidance Note 5. Sheffield: Training Agency.

Bailey, T. 1997. Changes in the nature of work: Implications for skills and assessment. In Workforce readiness, ed. by H. F. O’Neil (Jr). New Jersey: Lawrence Erlbaum Associates.

Barrett, J. 1986. Evaluation of student teachers. ERIC Digest 13. ERIC Document Reproduction Service, ED278658.

Barry, K. and L. King. 1998. Beginning teaching and beyond. 3rd ed. Wentworth Falls, NSW: Social Science Press.

Brophy, J. E., C. L. Coulter, W. J. Crawford, C. M. Evertson and C. E. King. 1975. Classroom observation scales: Stability across time and context and relationships with student learning gains. Journal of Educational Psychology 67 (6):873-881.

Conklin, R. C. 1985. Teacher competency testing: The present situation and some concerns on how teachers are tested. Education Canada 25(Spring):12-15.

Department of Education. 1998. Final report of the Technical Committee on the Revision of Norms and Standards for Educators. Pretoria, Republic of South Africa: Department of Education.

- 2000. Norms and standards for educators. Government Gazette 415 (20844). Pretoria, Republic of South Africa: Department of Education. http://education.pwv.gov.za/content/ documents/170.pdf.

Department of Education and Training. 2003. Quality teaching in NSW public schools: Discussion paper. Sydney: New South Wales Department of Education and Training.

Eltis, K. J. 1997. Workforce competencies of teachers. In Workforce readiness, ed. H. F. O’Neil (Jr). New Jersey: Lawrence Erlbaum Associates.

Evans, G. 1994. The knowledge base of beginning teachers: competence and competencies, in Knowledge and competence for beginning teachers. Report of a policy development initiative. Toowong: Queensland Board of Teacher Registration.

Fennell, E. 1990. TAG Guidance Note Number 5: Assessment of competence. Competence \& Assessment Compendium No. 1:42-43.

Fletcher, S. 1997. Competence-based assessment techniques. 2nd ed. London: Kogan Page.

Fraser, W. J. 1995. Teaching and assessment of competencies and skills. Personeel Bulletin, 19 (2):7-17.

- 1996. Competence-based teacher education and the dilemma of the distance education practitioner. Progressio 18 (1):74-90.

Foyster, J. 1990. Getting to grips with competency-based training and assessment. Leabrook: TAFE National Centre for Research and Development Ltd.

Glass, G. V. 1978. Standards and criteria. Journal of Educational Measurement 15 (4):237-261.

Good, T. and J. Brophy. 1991. Looking in classrooms. 5th ed. New York: Harper Collins.

Hollins, E. R. 1993. Assessing teacher competence for diverse populations. Theory into Practice 32 (2):93-99.

Ilot, I. and R. Murphy. 1999. Success and failure in professional education: Assessing the evidence. London: Whurr. 
Killen, R. 2002. Outcomes-based education: Principles and possibilities. Interpretations 35 (1):1-18.

- 1991. Modifying the clarity behaviours of experienced teachers through structured feedback. The South Pacific Journal of Teacher Education 19 (2):103-115.

Killen, R. and C. Richards. 1996. A new approach to teacher education at the University of Newcastle. Paper presented at the 26th Annual Conference of the Australian Teacher Education Association, Launceston, July.

Killen, R. and P. Steyn. 2001. Reconstruction of meaning during group work in a teacher education programme. South African Journal of Higher Education 15 (1):61-67.

Luke, A., B. Lingard, J. Ladwig, M. Mills, D. Hayes and J. Gore. 1998. School reform longitudinal study: interim report. (Submitted to Education Queensland by the Graduate School of Education, The University of Queensland). Brisbane, Australia: University of Queensland.

Marais, P. and C. Meier. 2004. Hear our voices: Student teachers' experiences during practical teaching. Paper delivered at Educational Association of South Africa Conference, RAU University, 13-15 January 2004.

Marland, P. 1994. Research on professional knowledge and competence for beginning teaching: A synthesis of some Queensland studies. In Knowledge and competence for beginning teaching. Toowong: Queensland Board of Teacher Registration.

Marquand, J. 1998. Occupational standards and business ethics. In Key qualifications in work and education, ed.W. J. Nijhof and J. N. Streumer. Dortrecht: Kluwer Academic.

Matshidiso, E. T. and M. C. Teu. 2002. DAS: Does it develop? A paper presented at the Annual Conference of the Southern African Society for Education, Pretoria, 26-28 September.

Messick, S. 1984. The psychology of educational measurement. Journal of Educational Measurement 21:215-238.

Mitchell, L. 1990. Assessing occupational competence: What does it mean in practice? Competence \& Assessment Compendium No. 1:34-36.

Norris, N. 1991. The trouble with competence. Cambridge Journal of Education 21 (3):331341.

Republic of South Africa. 1995. White paper: Education and training in a democratic South Africa. Pretoria: Government Printer.

Ryan, J. M. and T. M. Kuhs.1993. Assessment of preservice teachers and the use of portfolios. Theory into Practice 32 (2):75-81.

Saunders, E. 2000. Assessing human competence. Johannesburg: Knowledge Resources.

Siebörger, R. and H. Macintosh.1998. Transforming assessment. Cape Town: Juta.

Spady, W. 1994. Outcome-based education: Critical issues and answers. Arlington, VA: American Association of School Administrators.

_.1998. Paradigm lost: Reclaiming America's educational future. Arlington, VA: American Association of School Administrators.

Spady, W. and A. Schlebush. 1999. Curriculum 2005. A guide for parents. Goodwood: Renaissance.

Stedman, C. H. 1985. Testing for competence: Lessons from health professions. The Educational Forum 49 (2):199-210.

Stodolsky, S. S. 1984. Teacher evaluation: The limits of looking. Educational Researcher 13 (9):11-18.

Teu, M. C. and M. W. Legotlo. 2002. Quality assurance: Are public schools ready? A paper presented at the Annual Conference of the Southern African Society for Education, Pretoria, 26-28 September. 
Understanding Knowledge. 1990. The final report of the identifying and accrediting relevant knowledge in the building society sector project. Briefing Series Number 3. Barbara Shelborn Developments Ltd.

University of Pretoria and National Education Group. 2000. Teaching and training studies 710. Study Guide for the B.Ed. Degree, Education Management, Faculty of Education, University of Pretoria. Johannesburg: National Education Group (Pty) Ltd.

van der Wagen, L. and B. Ridley. 1997. Your guide to training and assessment in the National Qualifications Framework. Pretoria: Kagiso Publishers EBA (Pty) Ltd.

Wiersma, W. and T. Gibney. 1985. Observation as an approach to measuring teacher competency. Action in Teacher Education 7:59-67.

Wittrock, M. C. ed. 1986. Handbook of research on teaching. 3rd ed. New York: Macmillan.

Whitty, G. and E. Willmott. 1991. Competence-based teacher education: Approaches and issues: Cambridge Journal of Education 21 (3):309-318. 